\title{
eSport Building Design Role In Introducing Its Activities
}

\author{
Y E Sutantio ${ }^{1}$, E Poedjioetami ${ }^{1}$, and W W Widjajanti ${ }^{1}$ \\ ${ }^{1}$ Architecture Department, Civil and Planning Faculty, Institut Teknologi Adhi Tama Surabaya \\ yosivanerlanda@gmail.com
}

\begin{abstract}
. esport has the meaning of electronic sports, which the aspect of the sport is all facilitated by the electronic system. The definition of esport is a sport that does not compete physically, but is more concerned with strategy and competed online via computer, so players from each team can compete without face to face. In its development, esport enthusiasts from year to year increase, but unfortunately this is not balanced with the existence of facilities that can support the development of esport. Some facilities are often used is a place with different functions. There is still no building with a special function that is used for esport activities. The purpose of this research is to create a building facility that can accommodate the esport activities. Use method / application micro-concept of form is transformative, dynamic macro concept, and modern architectural theme, Result of building design that can present the function esport visually. So that building can be characteristic for esport building.
\end{abstract}

\section{Introduction}

Rai (2009) in the journal "Future Perspective on Next Generation e-Sport Infrastructure and Exploring Their Benefits" said that esport means sport that are played competitively through computer and video games played as competitive sports over the Internet and a local area network (LAN), and are provided to users through a TV relay broadcasting system and the internet [1]. Hallmann (2017), in his journal "esport Competitive sport or recreational activity" said that in 2022 esport will be competing at the Asian Games in China [2]. So that more and more peoples are interested in becoming professional gamers or esport athletes. In othe side, esport become a bussiness chance for some sponsors as business land by providing support to several competing teams.

The growing development of esport that is increasingly high, also affects the esport in terms of business, especially relating to the venue or place that is used for activities related to esport by utilizing existing buildings from ticket sales, souvenirs, and others. Jenny (2018) in her journal "esport venues: A new sport business opportunity" explained that eSports stadium attendance had seen substantial growth over the last few years [3].

Borowy (2012) in his thesis stated that the computer and video game industry is expected to grow from $\$ 67$ billion in 2012 to $\$ 82$ billion in 2017, quoted from DFC Intelligence [4]. So that in terms of economics esport also affects the field quite significantly. Several universities in the world have also opened this eSport department, quoted from the journal "Embracing eSport Education and Research Opportunity" by Daniel (2017), such as the University of California Irvine who has built and sponsored the development of eSport arena [5].

Based on these data, it can be concluded that the development of export is getting bigger, but there is still no one of the venues that can overshadow this esport activity specifically, especially in introducing the activities contained therein. However, there are limited sources of journals or other sources that explain building and building design related to eSport. Given the results of the case studies of several stadiums that have been used for eSport activities are stadiums designed for other sports, so the appearance or impression shown does not show esport identity. Through this research will be studied how to display esport buildings that are able to show activities in it. 


\section{Methods}

The research method used is descriptive method and analysis method, by taking the data sources from literature, and direct surveys. Descriptive method is used to explain information that has been obtained, which is analyzed according to the need for the designs that have been obtained.

From the data sources are obtained then analyzed with "programming" method, which was initiated by Donna P Duerk (1993) [6]. The data sources are used as "facts", which explain the conditions on the studied object that has been carried out. Then give attention, question, topics, or circumstances that require for design answer (Issues). After that, do the analysis and give the final statement to determine the determine the direction of the design (Goals). Provide the stage or ways of taking action to achieve these goals (performance Requirements), which are realized in the form of a sketch (Partial Idea) which the designer can determine the design concept used.

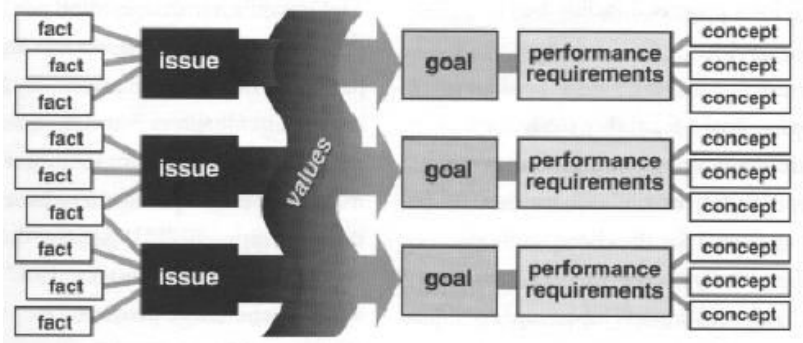

Figure 1. "Programming” Diagram, Donna P Duerk

From the method that has been used, it can be obtained concepts that can be used as a reference for designing. The chosen theme for design is Modern Architecture, because it can display building aesthetics also pay attention to the functions and contents of the space in it. The chosen macro concept is visually dynamic, because with a dynamic impression design it can visually present the function of the esport, which seems not monotonous. The chosen concept of form is transformative, because of the form composition with transformative method is expected to display a new form that can also present the function of esport, and the micro concept of room is representative with the aim of presenting room with esport functions.

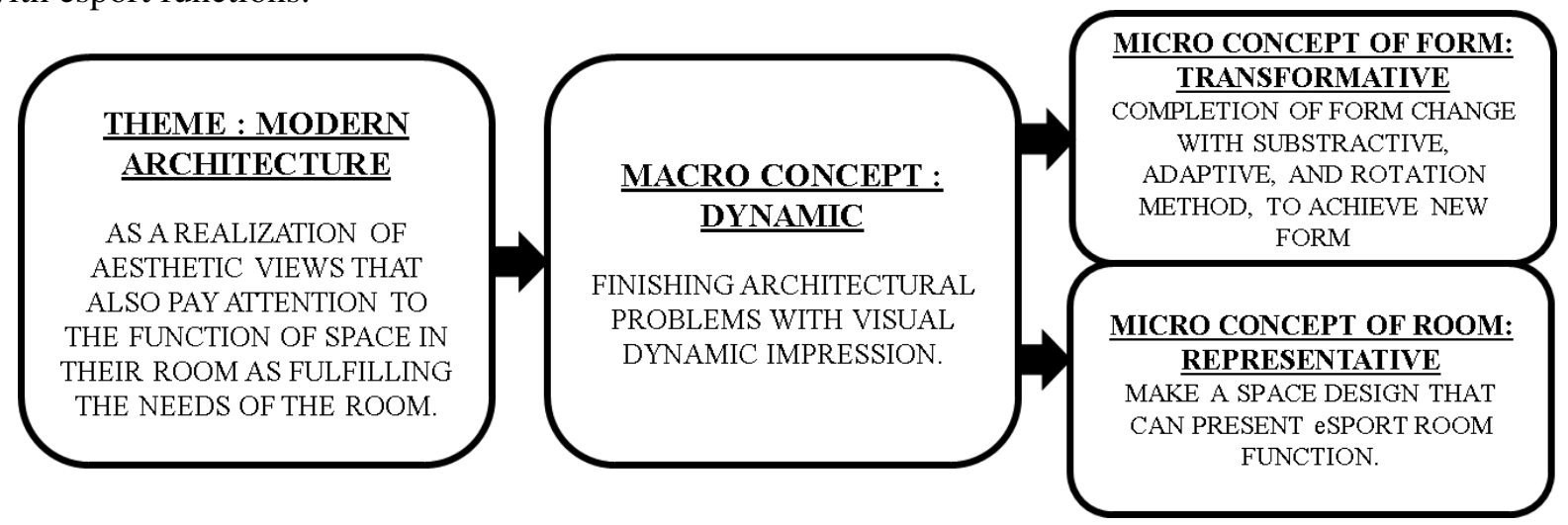

Figure 2. Design Concept Diagram

\section{Result and Discussion}

\subsection{Transformation Related to eSport Building Design}

In the concept method that has been explained previously, it is known that the theme used for design of the building with esport function uses Modern Architecture theme. Modern architecture is chosen because it is considered in accordance with the purpose of the design, not only pay attention to the appearance of physical beauty facade in the building, but also pay attention to the function of room in it. So that the building can present the function of the building.

The chosen macro concept is "dynamic", in this case the visual sense is visually dynamic, which is giving tha appearance of a building that has a visually dynamic impression (not monotonous, rigid, and 
too formal), and achieved with the application of the transformative micro concept, that is giving form changes through substractive methods (reduction), adaptive (addition) or rotation. This transformative process is intended to show new building forms that do not have the same form with other buildings, so that the building's impression becomes attractive, and unique that can attract visitors.

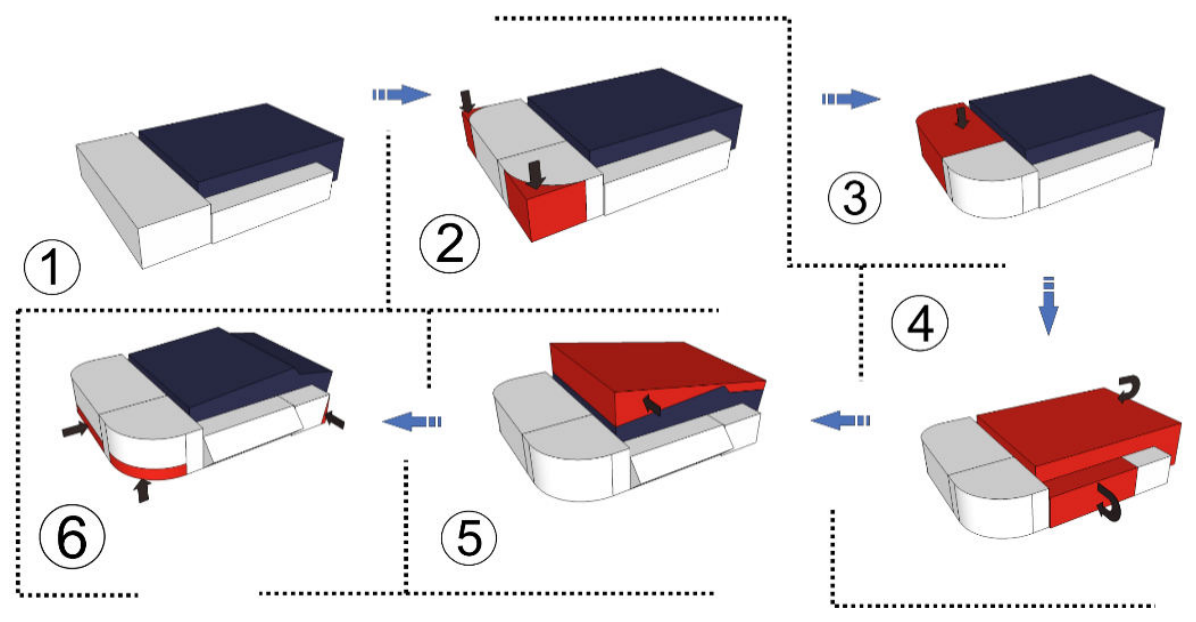

Figure 3. Form Transformation Process

To present building functions that are more directed to the function of esport buildings by using additional line on the facade of the building. These simple liness made of vertical, horizontal and diagonal lines are taken from the lines shape in the electronic device circuit. This is considered appropriate for presenting the function of esport that has a direct relationship with electronic devices, which have circuit line identities that are easily recognizeable by people. Laying of these building lines is adjusted to the direction of the length or width of the building to suit the placement of the facade lines. Placement of line that describes electronic device circuits in buildings, can be seen in figure 5 .
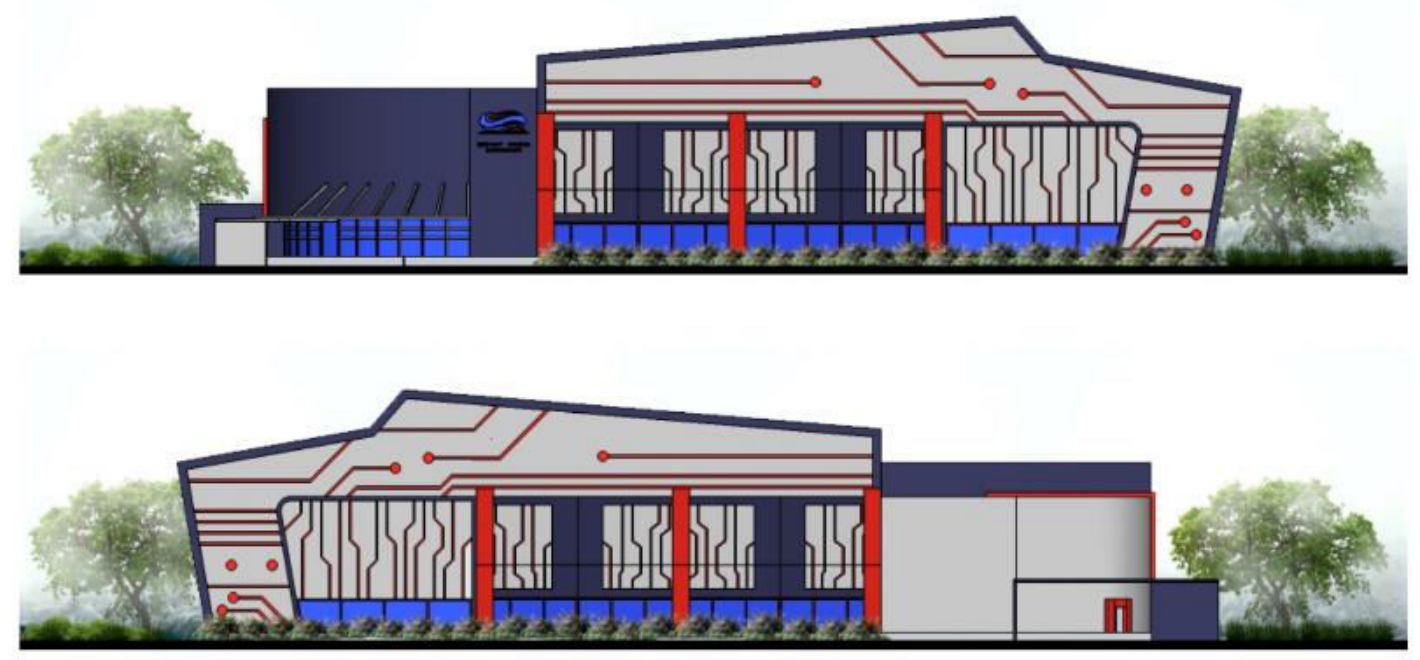

Figure 4. Indoor Arena Facades 


\section{ICATECH ITATS'=}

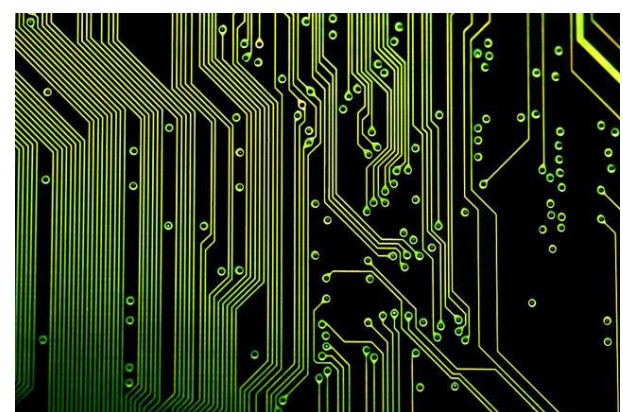

Figure 5. Line Shape of Electronic Device Circuits

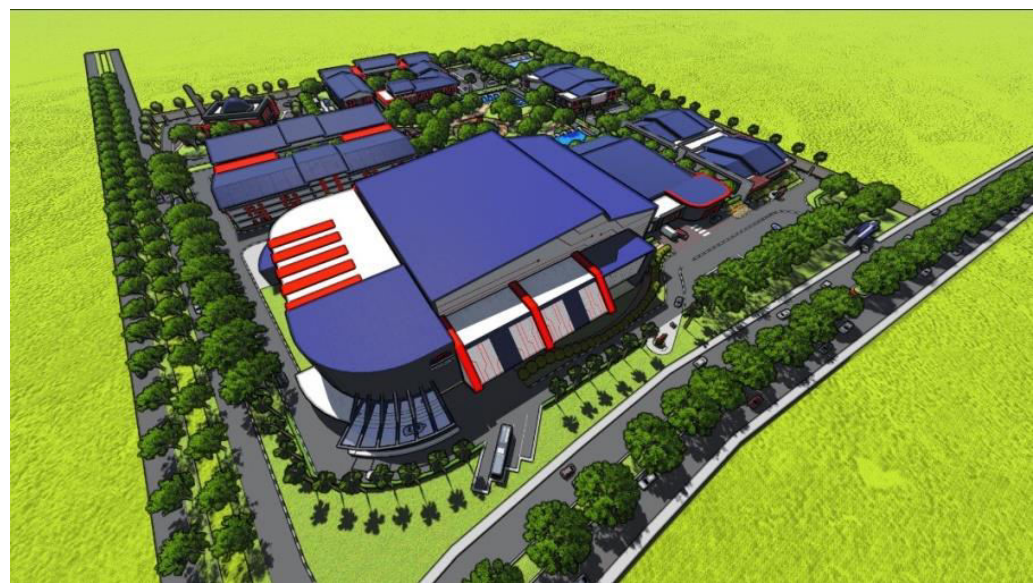

Figure 6. Bird Eye Perspective

Processed room by providing a representative concept to present the function of space in it. Processed representative room embodied in spatial arrangement arranged in such a way that resembles a building with similar functions. Indoor arena buildings, which have functions similar to stadium or other arena buildings, with arena positions placed in the middle, and surrounded by stands and other supporting rooms around it. Space layout design for indoor arena buildings can be seen in figure 7. In the picture it can be seen that the arena position is in the middle of building, which is surrounded by press conference rooms, security rooms, committee rooms, backstage participants, medical rooms, and some service room as a supporting room. 


\section{ICATECH ITATT'S}

The $1^{\text {st }}$ International Conference on Advanced Engineering and Technology - 2018
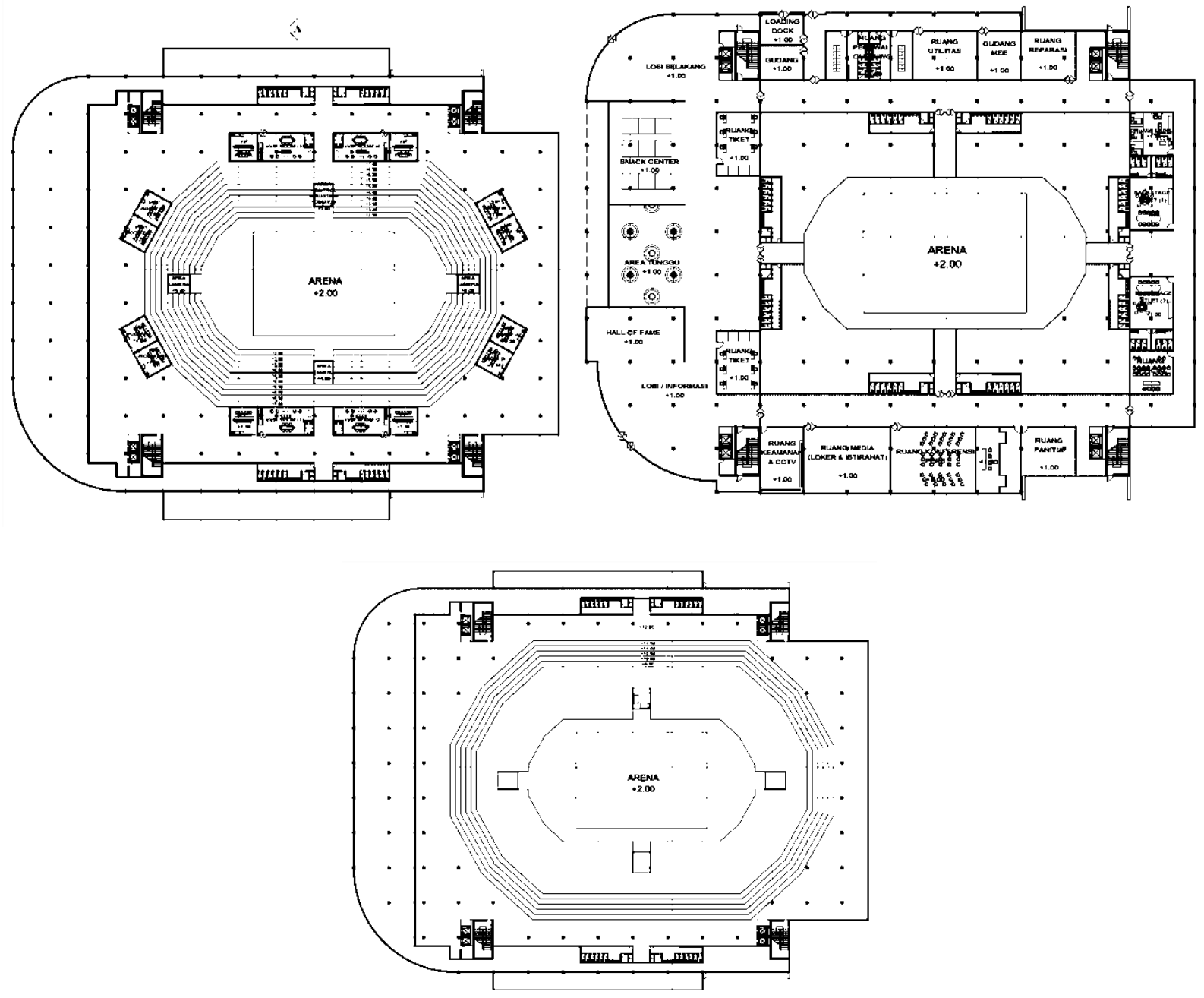

Figure 7. Indoor Arena Floor Plan $\left(1^{\text {st }}\right.$ Floor $-2^{\text {nd }}$ Floor $-3^{\text {rd }}$ Floor $)$

In addition, a representative concept is applied to the impression of room (interior) with the application of using colors that are also used on the exterior of the building. The colors were taken fro one of the colors of the esport logo, red and blue, which presented two teams that used to compete in esport, the red team and the blue team. The application of other colors such as white as the color of the wall, as a neutral color.

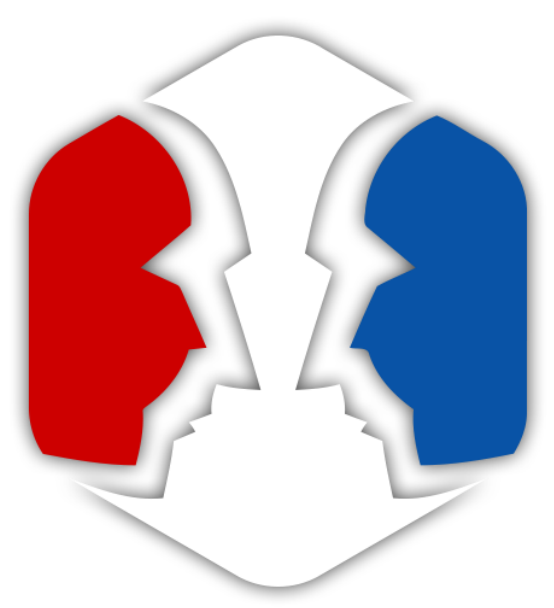

Figure 8. esport arena logo

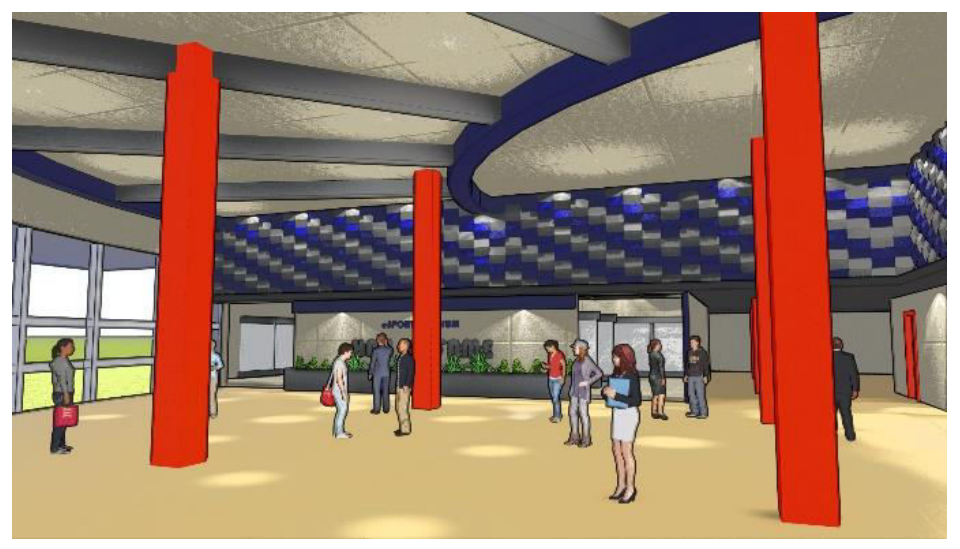

Figure 9. Sketch of Room : Indoor Arena 


\section{ICATECH ITATS':}

\section{Conclusion}

The growing development of esport lately has not been matched by the provision of special facilities that can facilitate esport activities. Because of this, a venue is needed specifically for esport activities. The design method used is a "programming" method to achieve the design concept is suitable for the design project. Design emphasis is made on the provision of building designs that can introduce esport activities. Emphasis on the appearance of buildings that can present the function of esport. Building design which also gives the impression and function of room which also present esport. In addition, the interior impression is also shown to support the atmosphere or impression that corresponds to the esport tittle.

\section{References}

[1] L. Rai and G. Yan, "Future Perspective on Next Generation e-Sports Infrastructure and Exploring Their Benefits," Int. J. Sport. Sci. Eng., vol. 3, no. 1, pp. 27-33, 2009.

[2] K. Hallmann and T. Giel, "eSports - Competitive sports or recreational activity?," 2017. .

[3] Jenny, S. E., M. C. Keiper, and B. J. Taylor, "eSport Venues A New Sport Bussiness Opportunity," J. Appl. Sport Manag., vol. 10, no. 1, 2018.

[4] M. Borowy, "Public Gaming : eSport and Event Marketing in the Experience Economy," 2012.

[5] D. C. Funk, A. D. Pizzo, and B. J. Baker, "eSport management: Embracing eSport education and research opportunities," J. Sport Manag. Rev., pp. 7-13.

[6] D. P. Duerk, Architectural Programming: Information management for design. New York: Van Nonstrand Reinhold Company, 1993. 